\title{
8
}
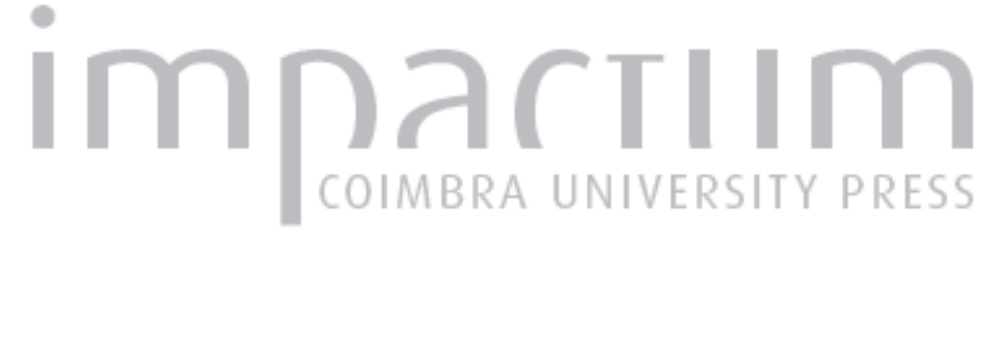

\section{O uso e o significado do termo dactilioteca em Portugal nos registos latinos e modernos}

\author{
Autor(es): $\quad$ Morais, Rui; Oliveira, Amélia \\ Publicado por: Imprensa da Universidade de Coimbra \\ URL \\ persistente: \\ URI:http://hdl.handle.net/10316.2/37522 \\ DOI: \\ DOI:http://dx.doi.org/10.14195/0872-2110_59_6 \\ Accessed : $\quad$ 26-Apr-2023 12:37:57
}

A navegação consulta e descarregamento dos títulos inseridos nas Bibliotecas Digitais UC Digitalis, UC Pombalina e UC Impactum, pressupõem a aceitação plena e sem reservas dos Termos e Condições de Uso destas Bibliotecas Digitais, disponíveis em https://digitalis.uc.pt/pt-pt/termos.

Conforme exposto nos referidos Termos e Condições de Uso, o descarregamento de títulos de acesso restrito requer uma licença válida de autorização devendo o utilizador aceder ao(s) documento(s) a partir de um endereço de IP da instituição detentora da supramencionada licença.

Ao utilizador é apenas permitido o descarregamento para uso pessoal, pelo que o emprego do(s) título(s) descarregado(s) para outro fim, designadamente comercial, carece de autorização do respetivo autor ou editor da obra.

Na medida em que todas as obras da UC Digitalis se encontram protegidas pelo Código do Direito de Autor e Direitos Conexos e demais legislação aplicável, toda a cópia, parcial ou total, deste documento, nos casos em que é legalmente admitida, deverá conter ou fazer-se acompanhar por este aviso.

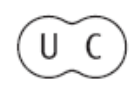


COIMBRA • 2014

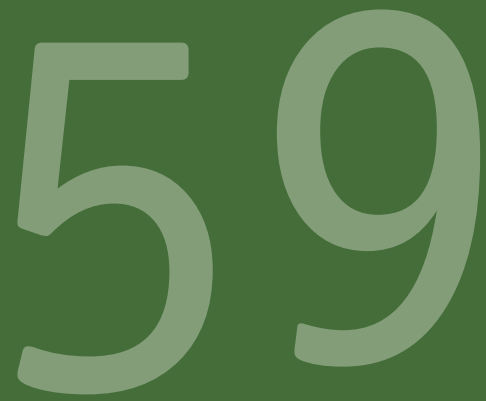

\title{
BOLETIM DE
}

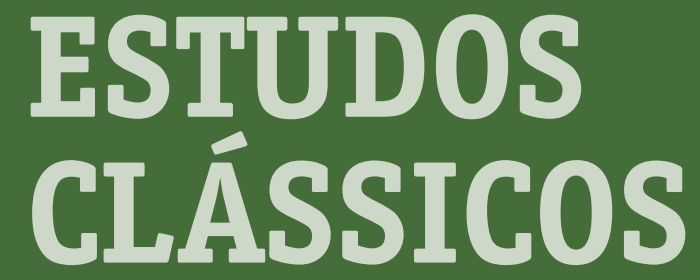

\author{
ASSOCIAÇÃO \\ PORTUGUESA \\ DE ESTUDOS \\ CLÁSSICOS \\ INSTITUTO \\ DE ESTUDOS \\ CLÁSSICOS
}




\title{
0 USO E 0 SIGNIFICADO DO TERMO DACTILIOTECA EM PORTUGAL NOS REGISTOS LATINOS E MODERNOS
}

\section{(THE USE AND MEANING OF THE TERM DACTYLIOTHECA IN PORTUGAL, IN LATIN SOURCES AND IN MODERN SPEECHES)}

RUI MORAIS

UP - CECH

\author{
AMÉLIA OLIVEIRA \\ INTÉRPRETE
}

Resumo: Estuda-se a utilização do termo dactilioteca nos autores da antiguidade clássica romana e o seu uso e significado nos registos latinos e modernos em algumas obras de referência europeias. Constata-se que este termo começa a ganhar maior popularidade no século XVIII e vai sofrendo uma alteração do seu significado como resultado do estudo das gemas, cada vez mais popular. Entre nós, este termo, já utilizado em dicionários em latim, pelo menos a partir do século XVI, vai sendo referido na dicionarística portuguesa, ainda que cada vez de forma mais sucinta.

Palavras chave: dactilioteca, dicionários, gemas

Abstract: We study the use of the term dactyliotheca in authors of Roman classical antiquity and the use and meaning of the term in Latin and modern records in some prominent European books. The study reveals that this term gains popularity in the eighteenth century and 
undergoes a change in meaning as a result of the study of gems, which is becoming increasingly popular. In Portugal, this term, already seen in Latin dictionaries since at least the sixteenth century, is mentioned in Portuguese dictionaries, albeit over time all the more succinctly. Keywords: dactyliotheca, dictionaries; gems

\section{DACTILIOTECA OU DACTILOTECA, UMA PALAVRA ARTIFICIAL E 0 SEU SIGNIFICADO NAS OBRAS DE CONSULTA}

Nesta breve análise, interessa-nos saber como é que o termo dactilioteca ou dactiloteca ${ }^{1}$ se disseminou no passado, como se modificou com o correr dos anos e quando é que finalmente desapareceu da linguagem comum. Esta análise parte das obras de consulta a partir do século XVIII.

A primeira referência surge em Plínio (Nat. 37, 11), quando no seu capítulo dedicado às gemas ele refere uma coleção de pedras preciosas, "quod peregrino appellant nomine dactyliothecam" (aquilo que se descrevia mediante o termo estrangeiro de dactilioteca). Parece, no entanto, que não se trata de um termo estrangeiro, mas antes de uma palavra artificial, uma vez que não há nenhuma fonte grega que comprove a sua utilização (Bauer \& Bestle 2006: 57). Na mesma obra, Plínio (Nat. 37.5) refere Scaurus, o genro de Sula, como tendo sido o primeiro romano a possuir uma dactilioteca (dacthyliotheca). Famosa era também a coleção reunida por Pompeio Magno (Plínio, loc. cit.), outrora pertencente a Mitridates, que a teria depositado no templo de Júpiter Capitolino. Júlio César foi também um ávido colecionador de gemas, especialmente aquelas antigas atribuídas a famosos gravadores (Suetónio, Iul. Caes. 47). Plínio (loc. cit.) diz-nos que este teria depositado seis dactiliotecas no templo de Vénus

1 Não utilizaremos, senão excecionalmente, o termo dactiloteca, por ser menos frequente. 
Genetrix. Sabemos que Marcelo, filho de Octávia e sobrinho de Augusto, dedicou uma coleção de gemas no templo de Apolo Palatino (apud Richter 1968, 20-21; Casal García 1981, 11-22; Hening 1994, xi). Conhece-se ainda uma alusão ao termo dactilioteca em Marcial (Ep. Livro XI 59) quando, a propósito de Carino, um novo-rico que nem nos banhos, onde é fácil perder um anel, nem a dormir, os deixava de usar:

Carino traz em cada um dos seus dedos seis anéis e nem de noite os tira, nem quando toma banho. Porque será, perguntarão? Não tem cofre para os guardar (trad. Delfim Leão, vol. IV, 2004: 92).

Este é certamente o passo referido no Magnum Lexicon novissimum Latinum et Lusitanum de 1833 (Paris 1852), que indica que o termo está referido em Marcial, como "cofre, em que se guardão os anneis, e outras jóias"2.

Mais tarde esta expressão entrou na linguagem dos eruditos, nomeadamente dos humanistas, com o sentido que lhe foi atribuído por Plínio (Bauer \& Bestle 2006: 57).

O uso metafórico deste termo como uma pequena caixa ou armário para significar um livro impresso, que tinha entre duas capas uma colecção de pedras de gemas, deve-se a Abraham Gorlaeus (Abraham van Goorle = 1549-1608), um antiquário flamengo que publicou as gemas gregas e romanas do seu Gabinete de curiosidades com o título Dactyliotheca (Antuérpia 1609), (apud. Bauer \& Bestle 2006: 57) ${ }^{3}$. A maior parte dos

2 Magnum lexicon novissimum Latinum et Lusitanum : ad plenissimam scriptorum Latinorum interpretationem accommodatum, ex celeberrimorum eruditissimorumque philologorum locubrationibus depromptum ad normam praecipue magni lexici Latini et Lusitani ... Emmanuelis Pinii Cabralii et Josephi Antonii Romalii ... et aliorum valde locupletatum, correctum, et in novam prorsus formam redactum. Parisiis Prostat Venale Apud J-P.Aillaud, 1852.

3 Gorlaeus, Abrahami Gorlaei Antwerpiani Dactyliotheca seu annulorum sigillarium quorum apud Priscos tam Graecos quam Romanos usus... (Antuérpia: Plantin, 1609. Frontispiece copperplate engraving of the author by J. de Gheijn). 
exemplares reunidos nesta obra haviam sido maioritariamente adquiridos, um século antes em várias cidades italianas (Jaffé 1993: 103-120).

O primeiro dicionário setecentista que refere a palavra dactilioteca é de 1734, publicado por Johann Heinrich Zedler. Neste dicionário, intitulado Universal-Lexicon (um dos mais extensos do século XVIII), o termo é mencionado como uma caixinha de jóias; menciona ainda a

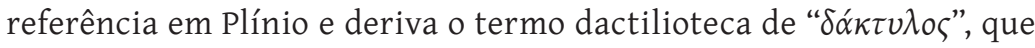
significa anel, e $\theta \eta ́ \kappa \eta$ (um contentor ou uma caixa). Assim a definição corresponde ainda ao significado antigo. Neste dicionário não há qualquer referência ao conceito de gema (apud. Bauer \& Bestle 2006: 57).

A enciclopédia editada por Jean le Rond d'Alembert e Denis Diderot ou Dictionnaire Raisonné des Sciences, des Arts et des Métiers ${ }^{4}$, uma das primeiras enciclopédias publicadas em França no século XVIII, refere em "pierre gravée" e de forma bastante pormenorizada a história e a produção de gemas. Este artigo é depois completado com um quadro em que se apresentam as ferramentas que eram utilizadas para o efeito. Na entrada "écrain" refere-se também um escaninho onde se guardam gemas e outros objectos afins. Deste artigo consta também a palavra dactilioteca, relacionando-a com as coleções de gemas dos romanos (apud. Bauer \& Bestle 2006: 57).

No dicionário germânico, "Deutsche Encyclopädie, oder Allgemeines Real - Wörterbuch aller Künste und Wissenschaften" (Dicionário Geral Real de todas as Artes e Ciências), que começou a ser publicado em 1778, já contém uma entrada dedicada ao conceito dactilioteca. 0 editor respeitando o uso contemporâneo do termo, refere que este significa, quer coleções de pedras preciosas talhadas, quer coleções das respetivas reproduções. No final deste artigo explica-se que normalmente esta palavra é utilizada para descrever a coleção de reproduções de enxofre

4 Em 1750, o título completo era "Encyclopédie, ou Dictionnaire raisonné des sciences, des arts et des métiers, par une société de gens de lettres, mis en ordre par M. Diderot de l'Académie des Sciences et Belles-Lettres de Prusse, et quant à la partie mathématique, par M. d'Alembert de l'Académie royale des Sciences de Paris, de celle de Prusse et de la Société royale de Londres". Os dados relativos a d'Alembert foram emendados, à medida que lhe foram conferidos novos títulos. 
ou em gesso que acompanham os materiais de uma aula e contém as respetivas explicações. Dão como exemplo a dactilioteca de Lippert, uma das mais divulgadas à época (Bauer \& Bestle 2006: 58).

Podemos então ver que este conceito começa a ganhar mais popularidade no século XVIII e simultaneamente sofre uma alteração do seu significado, o que não surpreende se tivermos em consideração o facto de a investigação das gemas se tornar cada vez mais popular e de as coleções de Dehn, Lippert e outros serem cada vez mais divulgadas (Bauer \& Bestle 2006: 58).

Não fica claro quem, no entanto, utilizou esta expressão pela primeira vez com o significado de coleção de cópias. Na segunda edição de Lippert, de 1755, cujo texto em latim foi elaborado por Johann Friedrich Christ, este termo foi adotado e transferido da ciência para descrever as gemas originais, passando agora a significar coleções de cópias (Bauer \& Bestle 2006: 58).

A expressão dactilioteca parece ter sido sobretudo do conhecimento de académicos e eruditos. As enciclopédias do século XVIII e do início do século XIX dão informações bastante pormenorizadas não só sobre a história, técnica e nível de investigação de gemas, mas também sobre as dactiliotecas antigas e suas reproduções modernas. Entre outras obras refira-se o conhecido Dicionário de antiguidades gregas e romanas, editado em 1859 por LL. D. William Smith. Na entrada deste dicionário o termo Dactyliotheca, retoma parte das referências clássicas acima referidas: "a case or box where rings were kept. (Mart. xi. 59.) The name was also applied to a cabinet or collection of jewels. We learn from Pliny (H. N. xxxvii. 5), that Scaurus, the step-son of Sulla, was the first person at Rome who had a collection of this kind, and that his was the only one till Pompey brought to Rome the collection of Mithridates, which he placed in the capitol".

\section{OS REGISTOS LATINOS EM PORTUGAL ATÉ AO SÉCULO XVI}

Os registos mais antigos em Portugal onde se refere o termo dactilioteca figuram nos dicionários bilingues de português-latim e de latim-português, 
verdadeiros testemunhos privilegiados da nossa memória linguística (Verdelho 2004: 413). Num dos mais antigos dicionários, o de português-latim do humanista Jerónimo Cardoso (c. 1510 - c. 1569), publicado em 1562, o termo, escrito sob a forma Dactylotheca(ae), figura como "o cofre dos aneis". Na reimpressão póstuma desta obra, preparada por Sebastião Stockammer em 1569/70, o termo adquire nova grafia, Dactilotheca(ae), e é referido como "a boceta pera guardar os aneis" (Verdelho 1994).

Numa das obras mais representativas da dicionarística dos Jesuítas, a Prosodia de Bento Pereira (1605-1681), publicada desde 1634 e com sucessivas reedições até 1750 (Verdelho 2004: 415, nota 6), o termo é referido da seguinte forma: "Dactyliotheca, ae, f. g. A dedeira, ou escritorio, ou gaveta, pera guardar os anneis. 2. 4. b. p. 1. Mart. 11. 60.!!”.

No dicionário Parvum lexicon latinum Lusitana interpretatione adiecta: ad usum Lusitanorum adolescentium in lucem... de Pedro José da Fonseca (1737-1816), editado em 1798, o termo aparece grafado como Dactyliothe$c a, a e$, f. e indicam-se as respetivas fontes clássicas: "Mart. Cofrezinho de guardar os anneis. Plin. Colar de muitas pedras preciosas".

Numa das obras mais monumentais da lexicografia portuguesa, o Vocabulario Portuguez e Latino publicado por Rafael Bluteau (1638-1734) entre 1712 e 1728, o termo "Dactylotheca, ae" está incluído no vocábulo - caxa: "Especie de arca, cuja coberta esta de por si, sem fechadura, \& sem engonços. Cappa, ae. Cic.§ Caxa. Tambor. Tocar caxas. Tympana pulsare. Tocar a caxa para fazer soldados. Tympani signo milites conscribere, ou engere.\$ Caxa do rosto. Oris ductus, us. Cic.\$ Caxa. Costumamos chamar àquelle, que entre homens de negocio recebe por todos, \& recolhe em si, como em caxa, todo o dinheiro. Pecuniae eorum, qui in eadem negotiatione sunt, custos, odis. Masc. ou administer, tri. Masc.\$ Caxa das reliquias dos Santos. Sacrarum reliquiarum theca, ou capsa, ae.\$ Caxa de tabaco, ou outra cousa, que se costuma trazer em caxas pequenas, de prata, marfim, ouro, aço, \& c. Tabaci capsula, ae. Fem.\$ Caxa de moldar. Vid. Moldar.\$ Caxa dos anèis. Dactylotheca, ae. Fem. Plin.§ Caxa do coche, da calexe, sege, \& c. He o corpo inteiro de madeira, quando està tirada do jogo. Moeda do Reyno de 
Tidore.\{(Lhes mandou ElRey dar a cada hum dez Caxas por dia, que valiaõ tres reaes da nossa moeda. Couto Dec. 5. fol. 219. col. 1.)\}".

\section{OS REGISTOS MODERNOS EM PORTUGUÊS}

Como nos indica Telmo Verdelho (1994), "na segunda metade do século XVIII e especialmente no fim do século, começam a surgir os primeiros dicionários modernos portugueses". No Diccionario encyclopedico publicado em 1868 por D. José Maria de Araújo Correia de Lacerda (vol. I) a palavra aparece grafada como "Dactyliothéca, s. f. (antiguid.) collecção de anneis ou de pedras gravadas".

O termo aparece também numa das obras tutelares da história da lexicografia portuguesa, o Diccionario de António de Morais e Silva (1755-1824), que teve 7 reedições ao longo do século XIX (1813, 1823, $1831,1844,1858,1877 / 1878,1891)$, sempre acrescentadas e melhoradas (Verdelho 1994). Na $7^{a}$ edição, a de 1877/78 (vol.I), a expressão aparece escrita como "Dactyliothéca, s. f. (do Gr. daktylios, annel, thêkê, armario) t. did. Armario contendo uma collecção de anneis e de pedras gravadas".

No Novo Diccionario da Língua Portuguesa de Cândido de Figueiredo, publicado no fim do século XIX, em 1899 (vol. I), o termo aparece como "Dactylotheca, f. museu ou, collecção de anéis, joias e pedras gravadas; pelle que involve cada um dos dedos dos mammíferos. (Do gr. daktulos+thekè)".

$\mathrm{Na} 10^{a}$ edição revista, corrigida, aumentada e atualizada do chamado Grande dicionário da língua portuguesa de António de Morais e Silva, editada em 12 vols entre 1949 e 1959, por Augusto Moreno, Cardoso Júnior e José Pedro Machado, retomando a obra do velho mestre do século XVIII, este vocábulo aparece duas vezes no volume 3, datado de 1951: "Dactilioteca, s.f. (de dactílio-+-teca). Museu ou depósito de anéis, jóias, pedras gravadas || Lugar onde se guardam. || Escrínio, caixa para jóias; Dactiloteca, s.f. (de dáctilo-+-teca). Arquivo ou colecção de dactilogramas. || Zool. Pele que envolve os dedos dos mamíferos. || Med. Dispositivo que mantém os dedos em extensão. 


\section{OS REGISTOS NO ÂMBITO DO NOVO ACORDO ORTOGRÁFICO}

No Grande Dicionário de Língua Portuguesa da Porto Editora (2010: 464), o termo dactilioteca/datilioteca é referido como s. f. 1 "coleção de pedras preciosas, anéis e jóias antigas; 2 lugar onde se guardam estes objetos". Segundo esta entrada do dicionário, o termo deriva do grego daktyliothéke, "coleção de anéis; estojo para anéis", pelo latim dactyliothēca, "idem".

No dicionário Antônio Houaiss da Língua Portuguesa (dir. Antônio Houaiss, Mauro de Salles Villar, Francisco Manoel de Mello, Lisboa: Círculo de Leitores, 2001), a palavra Dactilioteca figura como "s.f. (a. 1958 cf. MS10) 1 local onde se guardam anéis e jóias em geral < foi visitar a d.> 2. recipiente <escondeu a d. na gaveta> 3 p. met. coleção de anéis, jóias, pedras etc. <a sua d. vale uma fortuna> . ETIM lat dactyliotheca, ae 'cofre para guardar anéis, pedraria', adp. do gr. daktyliotheke' id.' ver dáctilo e teca-. PAR dactiloteca (s.f.)."

Como se pode ver, nesta asserção de Houaiss, a fonte ou primeira ocorrência da palavra numa obra lexicográfica é a $10^{\underline{a}} \mathrm{ed}$. do dicionário de Morais e Silva (1949-1958[1789]). Mas, como vimos, a primeira referência é ligeiramente anterior, pois já figura (para além dos registos latinos em Portugal até ao século XVIII) no Diccionario encyclopedico publicado em 1868 por D. José Maria de Araújo Correia de Lacerda.

\section{5.- APRECIAÇÕES FINAIS}

Depois deste breve excurso sobre o uso e significado da palavra dactilioteca em algumas obras de referência europeias e do uso deste termo nos registos latinos, modernos e atuais da dicionarística portuguesa, podemos concluir que, sobretudo a partir da segunda metade do século XIX, as referências a este termo tornam-se cada vez mais sucintas. Este é um sinal que o interesse em torno das coleções de gemas e das suas reproduções começa a decrescer. Mas não 
podemos esquecer que as entradas das enciclopédias e dos dicionários do século XVIII e XIX estavam sempre orientadas para um público erudito. Podemos então daqui deduzir que a população em geral não sabia o significado do termo dactilioteca e não conhecia também a investigação sobre as gemas.

A presença deste termo nos registos latinos em Portugal até ao século XVIII é também sugestiva de que este foi muito provavelmente introduzido por via dos humanistas europeus e por imitação dos dicionários de outras línguas onde esta palavra estava já documentada.

\section{BIBLIOGRAFIA EDIÇÕES, COMENTÁRIOS E TRADUÇÕES}

Ailluod, H., Suetónio: Vies des Douze Césars, Paris, 1931.

André, J., Pline L’Ancient, Paris, 1960.

Leão, D., Marcial: Epigramas (vol. IV, Livro XI), Lisboa. 2004.

\section{BIBLIOGRAFIA SELECTA}

Bauer, S. e Bestle, V. (2006), "Daktyliothek - ein Kunstwort und seine Verwendung in Nachschlagewerken", in Valentin Kockel und Daniel Graepler (ed.), Daktyliotheken. Götter \& Caesaren aus der Schublade. Antike Gemmen in Abdrucksammlungen. München: 57-59.

Boardman, J. (1970), Greek Gems and Finger Rings. Early Bronze Age to Late Classical. London.

Casal García, R. (1981), Aportación al estudio de la glíptica romana en España. Los entalles del Museo Arqueológico Nacional. Santiago de Compostela: Universidad de Santiago de Compostela.

Jaffé, D. (1993), "Aspects of Gem Collecting in the Early Seventeenth Century, Nicolas-Claude Peiresc and Lelio Pasqualini", The Burlington Magazine 135 (No. 1079): 103-120. 
Richter, G. M. A. (1968), The Engraved Gems of the Greeks and the Etruscans. A History of Greek Art in Miniature. Phaidon.

Smith, W. D. (1859, $3^{\mathrm{a}}$ ed.), A Dictionary of Greek and Roman Antiquities. London. Verdelho, T (2004). "Dicionários: testemunhos da memória linguística”. Encontros de Linguística Histórica e História da Língua Portuguesa. Porto: 413-427.

Verdelho, T. (1994). "Lexicografia", Lexikon der Romanistischen Linguistik (vol. VI,2). Tübingen: 673-692.

\section{ANEX0 5 \\ REGISTOS MODERNOS EM PORTUGUÊS}

José Maria A. A. Correia de Lacerda, Diccionario encyclopedico, 1868.

-Dactyliothéca, s. f. (antiguid.) collecção de anneis ou de pedras gravadas. (vol. I, p.789).

Morais Silva, 7ª ed., 1877.

-Dactyliothéca, s. f. (do Gr. daktylios, annel, thêkê, armario) t. did. Armario contendo uma collecção de anneis e de pedras gravadas. (vol.I, p.489).

Cândido de Figueiredo, 1899.

-Dactylotheca, f. museu ou, collecção de anéis, joias e pedras gravadas; pelle que involve cada um dos dedos dos dêdos dos mammíferos. (Do gr. daktulos+thekè). (vol. I, 3476).

Morais Silva, Grande dicionário da língua portuguesa, 10³. ed., vol. 31951.

-Dactilioteca, s.f. (de dactílio-+-teca). Museu ou depósito de anéis, jóias, pedras gravadas || Lugar onde se guardam. || Escrínio, caixa para jóias. (vol.III, p.796).

-Dactiloteca, s.f. (de dáctilo-+-teca). Arquivo ou colecção de dactilogramas. || Zool. Pele que envolve os dedos dos mamíferos. || Med. Dispositivo que mantém os dedos em extensão. (vol.III, p.798).

5 Agradecemos ao Professor Telmo Verdelho as preciosas anotações sobre os registos latinos e modernos nos dicionários portugueses. 


\section{REGISTOS LATINOS (ATÉ AO SÉC. XVIII)}

Cardoso, Dict. iuventuti studiosae, 1562, de Jerónimo Cardoso (c. 1510-1569). -Dactylotheca(ae). $O$ cofre dos aneis.

Cardoso, Dict. Latinolusitanicum, 1569-70, de Jerónimo Cardoso (c. 1510-1569). -Dactilotheca(ae). A boceta pera guardar os aneis.

Pereira, Prosodia, 1697, de Bento Pereira (1605-1681).

-Dactyliotheca, ae, f. g. A dedeira, ou escritorio, ou gaveta, pera guardar os anneis. 2. 4. b. p. 1. Mart. 11. 60.!!

Fonseca, Parvum Lexicon, 1798, de Pedro José da Fonseca (1737-1816).

-Dactyliotheca, ae, f. Mart. Cofrezinho de guardar os anneis. Plin. Colar de muitas pedras preciosas.

Bluteau, Vocabulario, 1712-28, de Rafael Bluteau (1638-1734).

- caxa. Especie de arca, cuja coberta esta de por si, sem fechadura, \& sem engonços. Cappa, ae. Cic.§ Caxa. Tambor. Tocar caxas. Tympana pulsare. Tocar a caxa para fazer soldados. Tympani signo milites conscribere, ou engere.§ Caxa do rosto. Oris ductus, us. Cic.§ Caxa. Costumamos chamar àquelle, que entre homens de negocio recebe por todos, \& recolhe em si, como em caxa, todo o dinheiro. Pecuniae eorum, qui in eadem negotiatione sut, custos, odis. Masc. ou administer, tri. Masc.§ Caxa das reliquias dos Santos. Sacrarum reliquiarum theca, ou capsa, ae.§ Caxa de tabaco, ou outra cousa, que se costuma trazer em caxas pequenas, de prata, marfim, ouro, aço, \& c. Tabaci capsula, ae. Fem.§ Caxa de moldar. Vid. Moldar.§ Caxa dos anèis. Dactylotheca, ae. Fem. Plin.§ Caxa do coche, da calexe, sege, \& c. He o corpo inteiro de madeira, quando està tirada do jogo. Moeda do Reyno de Tidore.\{(Lhes mandou ElRey dar a cada hum dez Caxas por dia, que valiaõ tres reaes da nossa moeda. Couto Dec. 5. fol. 219. col. 1.)\} 